\title{
Sizing stand-alone hybrid generation for seasonal irrigation pumping
}

\author{
Javier Carroquino ${ }^{1}$, Rodolfo Dufo-López ${ }^{2}$ and José L. Bernal-Agustín ${ }^{2}$ \\ ${ }^{1}$ C.P.S.-E.U.I.T.I.Z., University of Zaragoza \\ Calle María de Luna, 3. 50018-Zaragoza, Spain \\ e-mail: 125930@unizar.es \\ ${ }^{2}$ Electrical Engineering Department, University of Zaragoza \\ Calle María de Luna, 3. 50018-Zaragoza, Spain \\ Phone: +34976761921, fax: +34976762226, e-mail : rdufo@unizar.es, jlbernal@unizar.es
}

\begin{abstract}
This paper studies the generation to feed three stand-alone existing pumping systems in the province of Zaragoza (Spain), in the same area but with different consumption and irrigation needs. All of them are used only for half the year. We look for the optimal size of the generation mix, both economically and in reducing emissions.
\end{abstract}

For simulation and optimization the program used is HOGA (Hybrid Optimization by Genetic Algorithms). It is considered diesel generation, photovoltaic and wind as well as storage. As renewable resources are almost identical in the three locations, the magnitude of energy demand and schedule are the distinctive parameters of each facility. We considered how to choose the optimum angle of the PV array, the preference between the solar and wind and the desirability of whether or not the diesel generator.

The results show the importance of seasonality and time consumption profile to determine the generation mix and to choose the optimum inclination of the field of photovoltaic conversion. Results also show that most emissions reductions are not always obtained by removing the genset.

\section{Key words}

Hybrid optimization, stand-alone pumping, seasonal demand, photovoltaic sizing, emissions reduction, genetic algorithms.

\section{Introduction}

Facilities that use water pumps in irrigation systems are very often isolated from the electrical grid and rely on diesel generators for power. Hybrid generation may be a good option for them [1]. The three stand-alone pumping irrigation facilities Masatrigos I, Masatrigos II and Merla are situated in the province of Zaragoza (Spain). In all of them, irrigation is carried out for six months a year, between April and September, as in many crops in the Mediterranean area. This implies that renewable generation is not useful for another six months and it also implies the difficulty of sizing. The decision to reform the existing facilities or the installation of new ones faces the problem of comparing the different options for generation and storage. However, when demand is markedly seasonal, the best orientation for solar PV panels, the size of the storage and the possibility of hybrid power are not sufficiently studied. As it is very usual the utilization of diesel generators as the only source, it is desirable to study the feasibility of renewable energy integration, as well as improvements in the level of emissions of greenhouse gases can be obtained.

Genetic algorithms have been used lately as a means for optimization of photovoltaic systems and hybrid systems [2], [3]. HOGA software [4] is used to optimize both the sizing and control variables of the system, by mono and multi objective optimization [5].

The economic comparison was made by calculating the Net Present Cost (NPC) in a project horizon of 25 years. Solutions are sought less NPC. The following economic parameters have been introduced: current market prices, both components and operation and maintenance, fuel cost $0.7 € / 1$, general inflation rate $2 \%$, interest rate $6 \%$ and fuel inflation rate $6 \%$. Subsidies or $\mathrm{CO}_{2}$ emission rates were not considered.

\section{Load and resources}

\section{A. Electrical load}

Consumption and pumping schedules are shown in Table I. The relationship between the size of existing pumps and water needs involves more or less time for daily use.

Table I. - Pumps of the three installations

\begin{tabular}{|l|c|c|}
\hline & Pump power (kW) & Working hours per day \\
\hline Masatrigos I & 15 & 24 \\
\hline Masatrigos II & 9.2 & 24 \\
\hline Merla & 4 and 5.5 & 1.33 and 2.08 \\
\hline
\end{tabular}

For Merla, it is possible to vary the time of day when pumps work. The optimizations have shown that the best result is obtained when the two pumps are not operated simultaneously and concentrating consumption in the middle of the day, coinciding with the peak hours of sunlight.

\section{B. Wind resource}

Wind conditions are favored because they are located on land areas free of obstacles. The annual average wind speed at $30 \mathrm{~m}$ high are $4.75 \mathrm{~m} / \mathrm{s}$ and $5.25 \mathrm{~m} / \mathrm{s}$ for Masatrigos and Merla respectively. In both cases the roughness of the terrain is very low. 


\section{Solar resource}

The annual irradiation on horizontal plane is 1,682 $\mathrm{kWh} / \mathrm{m}^{2}$ in Masatrigos and $1,669 \mathrm{kWh} / \mathrm{m}^{2}$ in Merla according to data from PVGIS-CMSAF. Farmland favors solar horizon free of obstructions.

\section{Optimization of PV slope}

Simulations were carried out with a photovoltaic array insufficiently dimensioned, in terms of peak power, to remove the diesel generation. Varying other parameters of the PV field, we have seen that those values would reduce the energy required from the Diesel generator during the year, especially the slope. The data show that, for loads whose schedule is widespread (in the case of study, Masatrigos I and Masatrigos II), the largest photovoltaic penetration is obtained with an slope as to maximize the energy generated during the irrigation season. This slope differs from those obtained for the worst month and the optimal for the whole year, as shown in Table II.

Table II PV penetration increased as slope calculation method in Masatrigos I and II (extended hourly demand)

\begin{tabular}{|l|l|r|r|}
\hline $\begin{array}{l}\text { Calculating } \\
\text { slope }\end{array}$ & $\begin{array}{l}\text { Worst } \\
\text { month }\end{array}$ & $\begin{array}{l}\text { Optimal for } \\
\text { the year }\end{array}$ & $\begin{array}{l}\text { Optimal for } \\
\text { the season }\end{array}$ \\
\hline Slope & $39^{\circ}$ & $36^{\circ}$ & $18^{\circ}$ \\
\hline PV penetration & reference & $+1.3 \%$ & $+4.5 \%$ \\
\hline
\end{tabular}

However, when demand is concentrated in the middle of the day (in the case of study, in the installation of Merla), the improvement not only increases but also the sun's position results in a slight reduction in the optimum tilt angle. To calculate the optimal energy it is no longer taken into account the day of the year, but also the time of day. The result is shown in Table III.

Table III PV penetration increased as slope calculation method in Merla (concentrated hourly demand)

\begin{tabular}{|l|r|r|r|r|}
\hline $\begin{array}{l}\text { Calculating } \\
\text { slope }\end{array}$ & $\begin{array}{l}\text { Worst } \\
\text { month }\end{array}$ & $\begin{array}{l}\text { Optimal } \\
\text { for the } \\
\text { year }\end{array}$ & $\begin{array}{l}\text { Optimal } \\
\text { for the } \\
\text { season }\end{array}$ & $\begin{array}{l}\text { Optimal } \\
\text { for the } \\
\text { schedule }\end{array}$ \\
\hline Slope & $39^{\circ}$ & $36^{\circ}$ & $18^{\circ}$ & $15^{\circ}$ \\
\hline $\begin{array}{l}\text { PV } \\
\text { penetration }\end{array}$ & reference & $+1.3 \%$ & $+6.9 \%$ & $+7.2 \%$ \\
\hline
\end{tabular}

Since the seasonal and even hourly concentration of demand affect the optimal parameters of the system and a non negligible influence on the system performance, this become a factor taken into account in the design and sizing.

The high temperatures present during the irrigation season makes the influence of the temperature coefficient of power in the system performance to be greater than in a facility that works on an annual basis. The thermal behavior of the panels becomes more critical.

\section{The minimum economic}

\section{A. Masatrigos I and Masatrigos II}

The coincidence between the irrigation season and the months of highest solar irradiation has two opposing effects on the performance of photovoltaic generation. During non-irrigation season generation is not useful. During irrigation season output per $\mathrm{kWp}$ installed is high. In these facilities, the demand is continuously 24 hours a day. If there is excess PV production during the day, night use would be penalized by the loss (and increased cost) due to storage. As it is necessary in these facilities uninterrupted operation due to a small sized pump, percentage $0 \%$ of unserved energy has been considered.

From the results obtained (Fig. 1), the least NPC in 25 years is a mix of PV-diesel hybrid generation with battery storage.

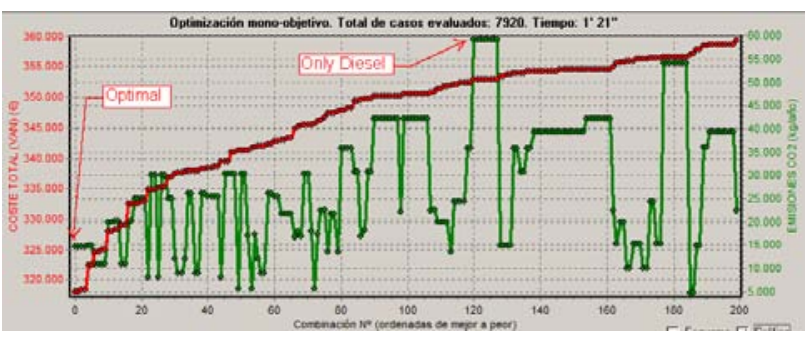

Fig. 1 . Masatrigos I: Solution Graphics

Use of diesel generator is substantially reduced, obtaining fuel economy and emission savings (Table IV).

Table IV Masatrigos I: system comparison chart

\begin{tabular}{|l|r|r|}
\hline & Only Diesel & \multicolumn{1}{|c|}{ Optimal } \\
\hline Net Present Cost $(€)$ & 352.950 & 318.051 \\
\hline Renewable energy fraction & $0 \%$ & $81 \%$ \\
\hline Genset operation (hours/year) & 4.392 & 1.019 \\
\hline $\mathrm{CO}_{2}$ emissions (kg/year) & 59.164 & 14.738 \\
\hline
\end{tabular}

In the graphs of the best day simulation (Fig. 2) and the worst day simulation (Fig. 3) it is shown the consumption (light gray), the diesel generation (black), PV production (yellow), the battery charge (green), battery discharge (blue), the state of charge (SOC) and its limits (different shades of red).

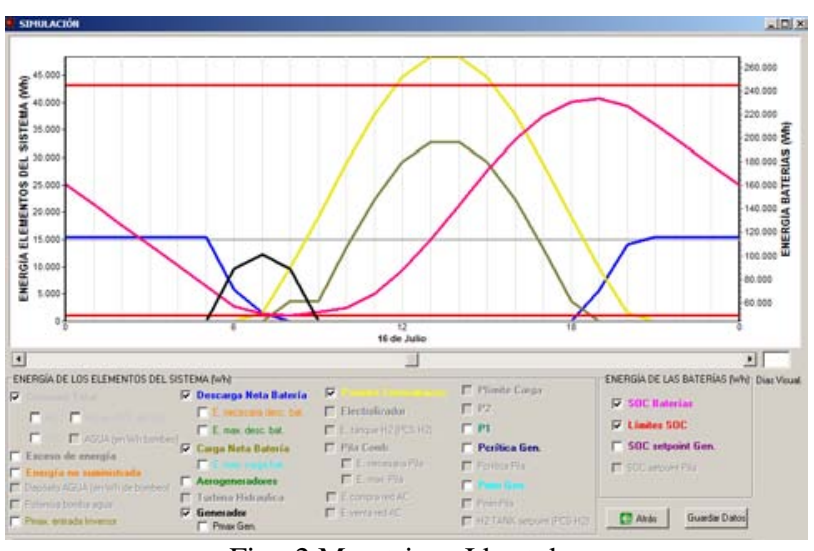

Fig. 2 Masatrigos I best day 


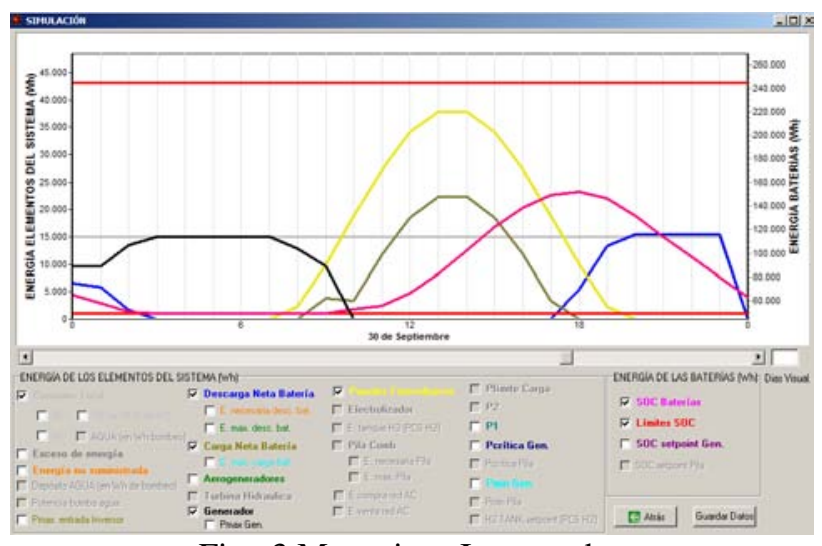

Fig. 3 Masatrigos I: worst day

To test the effect of seasonality of demand in the optimal generation mix, we have done the optimization of the same premises with consumption not seasonally adjusted, but extended throughout the year. Under these conditions, the result is Photovoltaic-Wind-Diesel hybrid generation.

The results in Masatrigos II are qualitatively very similar, differing by a factor of scale due to the smaller size of the load.

\section{B. Merla}

The irrigation season is the same as in Masatrigos. On the other hand, because of the sizing of the existing installation, irrigation is needed only for a few hours a day. This allows a range of management, changing the time zone of consumption. Concentrated demand during solar peak hours, it reinforces the positive effect on photovoltaic generation. Consequently, the optimal combination (lower NPC in 25 years) includes only a moderate photovoltaic generation and storage (Fig. 4).

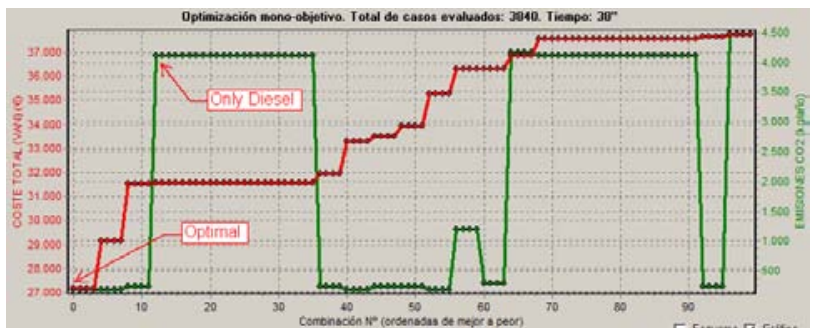

Fig. 4 Merla: Solution Graphics

Obviously, emissions from combustion are avoided, leaving only those relating to the life cycle of the facility (manufacturing, transport and scrapping) (Table V).

Table V Merla system comparison chart

\begin{tabular}{|l|r|r|}
\hline & Only Diesel & \multicolumn{1}{c|}{ Optimal } \\
\hline Net Present Cost $(€)$ & 34.163 & 27.179 \\
\hline Renewable energy fraction & $0 \%$ & $100 \%$ \\
\hline Genset operation (hours/year) & 642 & 0 \\
\hline $\mathrm{CO}_{2}$ emissions (kg/year) & 2.844 & 192 \\
\hline
\end{tabular}

In the graphs of best day (Fig. 5) and worst day (Fig. 6) and with the same colors and meanings in Figures 2 and 3 we see how the synchrony between consumption and photovoltaic generation allows direct use of energy. During the hours of consumption, energy generation comes from PV and batteries simultaneously. When consumption ceases, the battery recharges.

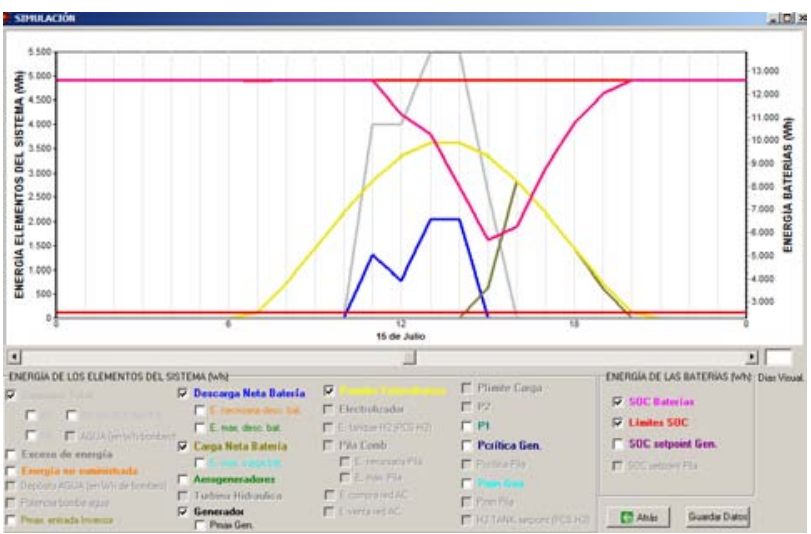

Fig. 5 Merla: best day

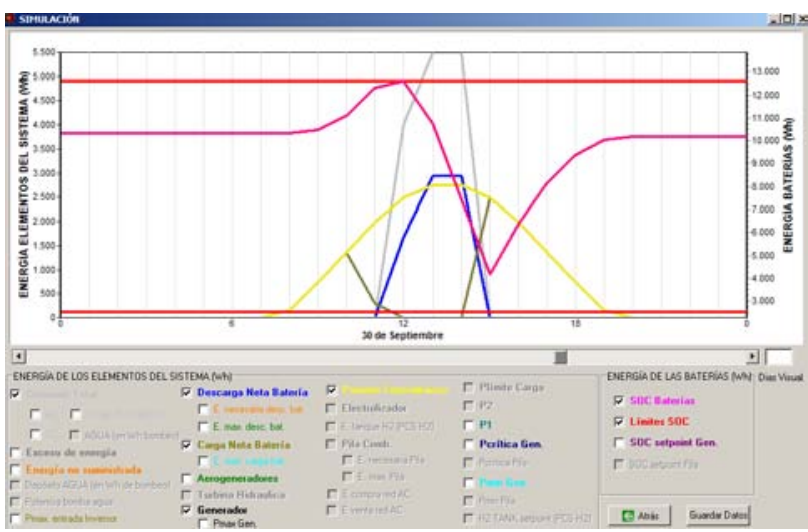

Fig. 6 Merla: worst day

If the demand is concentrated during the night, the least NPC in 25 years corresponds to the current situation, only with diesel generation. Found that demand management strongly influences the results, it must be considered as a variable or set of variables during the search for solutions and system design.

\section{Reducing emissions}

In stand-alone systems, even when the fraction is $100 \%$ renewable, it cannot be eliminated completely the contribution to the emission of greenhouse gases. There are still emissions from manufacturing, transportation and disposal throughout the life cycle of the system [6], [7], [8].

Optimizations have been made in order to minimize emissions. In Merla the minimum is achieved by eliminating the diesel generator with $100 \%$ renewable generation. However, in Masatrigos I and II, the minimum is obtained with a hybrid solution that uses the diesel at peak times, a few hours a year. The reason is that the increase of renewable generation needed to completely eliminate the Diesel is so great that emissions of their life cycle are greater than the fuel consumption for a few hours each year. In addition, the economic cost of the facility also is disproportionate. 


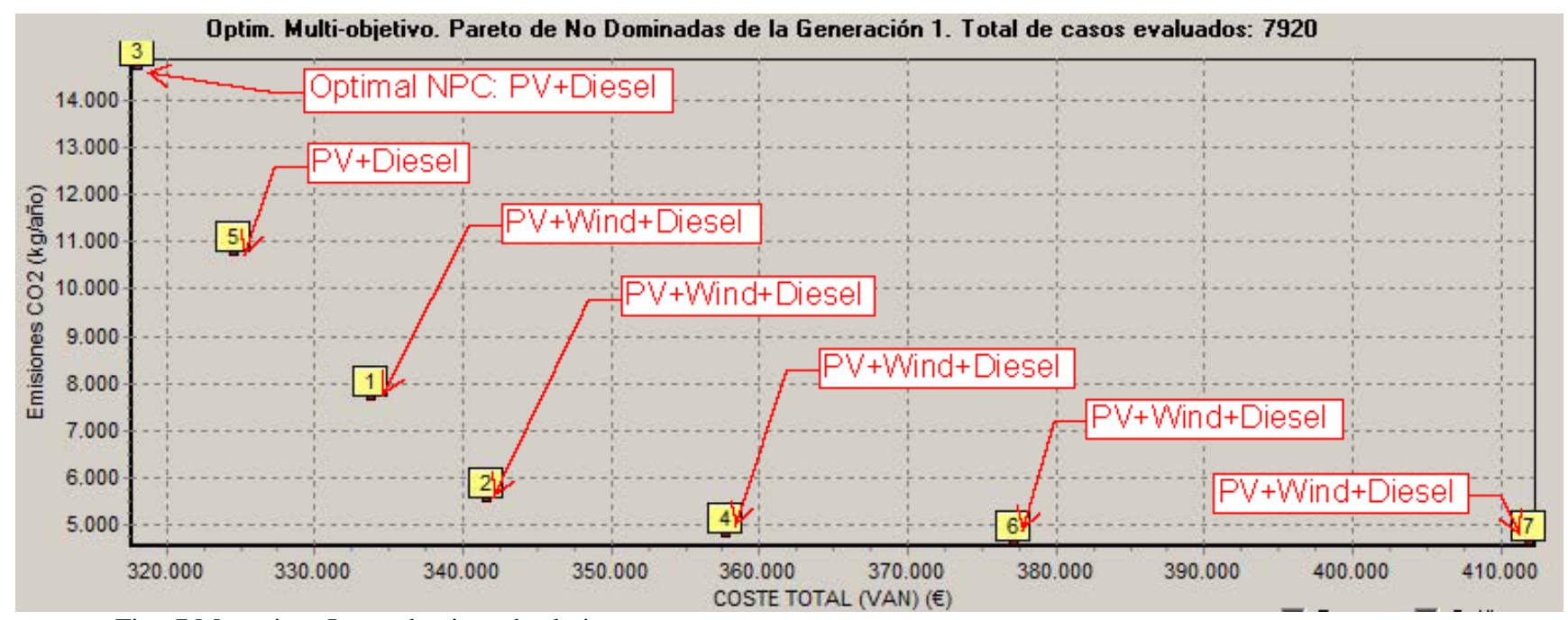

Fig. 7 Masatrigos I: non dominated solutions

Only non-dominated solutions in multiobjective optimization (NPC and emissions) Masatrigos I are shown in Figure 7. Diesel only option is not displayed because it is dominated by others. With respect to it, the economic optimum has already significantly reduced emissions. Further reduction of emissions occurs also incorporating wind generation. Solutions that exclude diesel generation do not appear. This is because there are others with lower emissions, which incorporate Diesel.

One possibility to use the energy that can produce renewable generation during the non-irrigation season is the production of hydrogen. However, in the simulations no profitability of the investment has been achieved. In the future evolution of the costs of hydrogen components (electrolyzer and fuel cell), this could change.

\section{Conclusion}

Stand-alone pumping facilities tend to be powered by diesel generators. In irrigation, in some regions and in some cultures the season of use may be limited to part of the year. When studying the feasibility of incorporating renewable generation, demand seasonality influences the performance of different types of generation. The search for the optimal solution should be made taking into account these conditions.

In the facilities studied, the irrigation season coincides with the months of highest solar radiation. This provides advantage for photovoltaic generation. If demand is also concentrated in the middle of the day, that advantage increases.

Hybrid solutions for renewable and Diesel generation can reduce costs in the long term, although the initial investment is much higher. They also significantly reduce emissions of greenhouse gases, as the diesel generator reduces its hours of operation. Under special conditions, such as the concentration of demand at hours of maximum solar irradiation, viable solutions can be obtained without diesel generator.

\section{Acknowledgement}

The data of the cases analyzed were provided by Bodegas Tempore and especially Victor Yago Aznar. Their collaboration was essential to provide the factual basis of this work.

\section{References}

[1] Mariano Sanz, José Francisco Sanz, Diego Botero, Marcos Navarro, Francisco J. Val, Julio J. Melero, Jesús Sallán, Andrés Llombart. Optimal integration of renewable energies in a pumping station for irrigation. IECON 02 Industrial Electronics Society, IEEE 2002 28th Annual Conference.

[2] José L. Bernal-Agustín, Rodolfo Dufo-López, Simulation and optimization of stand-alone hybrid renewable energy systems, Renewable and Sustainable Energy Reviews, Volume 13, Issue 8, October 2009, Pages 2111-2118

[3] Li Zhongshi; Zhou Wei; Yang Hongxing, One Novel Optimum Sizing Method for Solar Lighting System by Using Genetic Algorithm, 2009 International Conference on Energy and Environment Technology.

[4] José L. Bernal-Agustín, Rodolfo Dufo-López, Efficient design of hybrid renewable energy systems using evolutionary algorithms, Energy Conversion and Management, Volume 50, Issue 3, March 2009, Pages 479-489

[5] Rodolfo Dufo-López, José L. Bernal-Agustín, Multiobjective design of PV-wind-diesel-hydrogen-battery systems, Renewable Energy, Volume 33, Issue 12, December 2008, Pages 2559-2572

[6] R. García-Valverde, C. Miguel, R. Martínez-Béjar, A. Urbina, Life cycle assessment study of a $4.2 \mathrm{kWp}$ standalone photovoltaic system, Solar Energy 83, 2009, pp. 1434-1445.

[7] M. Watt, A. Johnson, M. Ellis, H. Outhred, Life-cycle air emissions from PV power systems. Progress in Photovoltaics: Research and Applications 6 (2), 1998, pp. 127-136.

[8] B. Fleck, M. Huot, Comparative life-cycle assessment of a small wind turbine for residential off-grid use, Renewable Energy 34, 2009, pp. 2688-2696. 